\title{
Fever in the returning traveller
}

DJ Bell

Consultant in Infectious Diseases and General Medicine, Brownlee Centre, Gartnavel General Hospital, Glasgow, Scotland, UK

\begin{abstract}
International travel is increasing and a significant number of travellers will develop a febrile illness during or shortly after their return from the tropics. The differential diagnosis is broad and a systematic approach to the management of these patients is required in order to establish the diagnosis and to initiate prompt and effective treatment. Fever may be due to infectious agents found only in tropical countries, or due to infections unrelated to travel and found worldwide. Important infections that should be considered in all returning travellers include malaria, dengue, enteric fever, rickettsial infections, and HIV seroconversion. Other diagnoses will be considered after a detailed history including countries visited with dates, activities undertaken and symptoms. At a minimum, all travellers from countries where there is malaria transmission should be tested repeatedly for malaria as well as having several sets of blood cultures taken. Many tropical infections are diagnosed serologically at specialist reference laboratories. Specialist advice on the investigation and management of returning travellers should be sought from infectious diseases physicians and microbiologists. Patients with malaria or enteric fever may deteriorate rapidly and travellers should be advised to seek prompt medical attention if they become unwell after travel to the tropics. This review will focus on some of the more important imported infections, diagnostic clues from the history, examination and investigations, and important considerations in their management.
\end{abstract}

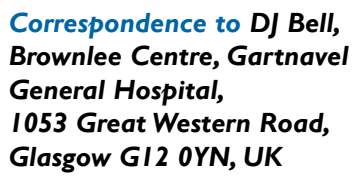

Correspondence to DJ Bell, Brownlee Centre, Gartnavel General Hospital, I053 Great Western Road, Glasgow GI 2 OYN, UK

tel. +44 (0) I 4 I 2 I I 0293 e-mail david.bell@ggc.scot.nhs.uk

KEYWORDS Fever, travel, malaria, typhoid

DECLARATION OF INTERESTS No conflict of interests declared.

\section{OVERVIEW}

International travel to tropical destinations is increasingly popular.The majority of these trips are for tourism, with the second largest group being UK residents visiting friends and relatives who live overseas. It is estimated that around $10 \%$ of travellers will seek medical attention while abroad or after they have returned home. In addition, migration into the UK has increased in recent years, and these individuals may present with fever or other health problems soon after arrival in the UK from a tropical country.

The list of potential infectious causes of fever in a returning traveller from the topics is long. However, for all of these patients the attending clinician should consider the following infections early on in their assessment:

- Malaria

- $\quad$ Enteric fever (typhoid and paratyphoid)

- Dengue

- HIV seroconversion

- Rickettsial infection

Some of these diagnoses may be disregarded if there has been no exposure, e.g. no travel to a malarious region, but this list at least serves as a reminder of some of the more important and common infections imported into the UK.
The annual number of cases of imported malaria in the UK is approximately I,500, with those visiting friends and relatives overseas accounting for more than $70 \%$ of these cases. There are between five and ten deaths each year, and in many cases of death there has been a delay in the diagnosis. It must also be remembered that many causes of fever in returning travellers are not specifically 'tropical infections'. These might include urinary tract infections, pneumonia, or viral infections like influenza, Epstein-Barr virus, or cytomegalovirus.

\section{HISTORY}

A detailed and structured history is the key to the diagnosis, appropriate investigation, and the initiation of prompt effective therapy. The following points should be considered:

I. Countries visited or transited through. Information resources on infections common in different geographical locations and current disease outbreaks are listed in the further reading list.

2. Dates of travel and illness onset. Most tropical infections will cause symptoms within one month of leaving the tropics, though malaria may present many months later. The dates of travel are also particularly important for viral haemorrhagic fever (VHF) risk assessment (see point 6). 
3. Pre-travel vaccinations and malaria prophylaxis taken, though one must be aware that none of these measures guarantee protection.

4. Type of travel. Clearly the range of exposures to different infections will be different for a healthcare worker who has been working in rural Africa and a tourist returning from a safari.

5. Activities while abroad. Table I lists risk factors or activities for exposure to specific infections.

6. VHF risk assessment. This group of viruses, including Lassa fever, Crimean-Congo haemorrhagic fever, Marburg and Ebola, pose a potential risk to healthcare workers because they can be transmitted person-toperson in body fluids. Because of the serious nature of these infections, most UK hospitals have policies for the risk assessment of travellers who present unwell within 21 days of leaving countries where these infections are found. High-risk patients require strict isolation and close liaison with infection diseases and microbiology specialists. These infections are very rare in the UK and specialist isolation facilities are available in Newcastle and London.

7. The patient's immune status. HIV-infected travellers are at increased risk of certain travel-related infections and opportunistic infections, including malaria, visceral leishmaniasis, gastrointestinal infection (bacterial and parasitic), and invasive fungal infections.

\section{EXAMINATION}

Many causes of fever will have no specific localising features. The examination should pay particular attention to look for hepatomegaly,splenomegaly,lymphadenopathy, rash, eschars (dark crusted bites), urticaria, jaundice, haemorrhage (e.g. conjunctival), and features of

TABLE I Infections associated with specific activities

\begin{tabular}{|l|l|}
\hline Activity & Possible causes of fever \\
\hline $\begin{array}{l}\text { Work in hospitals or } \\
\text { refugee camps }\end{array}$ & $\begin{array}{l}\text { Tuberculosis, HIV, viral } \\
\text { haemorrhagic fever (VHF), } \\
\text { typhus }\end{array}$ \\
\hline Sexual exposure & $\begin{array}{l}\text { HIV, hepatitis B and C, } \\
\text { syphilis, gonorrhoea }\end{array}$ \\
\hline Visit to African game park & Tick typhus \\
\hline Fresh water exposure & Schistosomiasis, leptospirosis \\
\hline Caving & Histoplasmosis, rabies \\
\hline $\begin{array}{l}\text { Contaminated food and } \\
\text { water/raw meat or fish }\end{array}$ & $\begin{array}{l}\text { Enteric fever, Shigella, } \\
\text { Salmonella, Campylobacter, } \\
\text { amoebiasis, helminth } \\
\text { infections, hepatitis A and E }\end{array}$ \\
\hline $\begin{array}{l}\text { Ingestion of unpasteurised } \\
\text { milk }\end{array}$ & Brucella, Listeria, Salmonella \\
\hline Animal contact & Brucella, Q fever \\
\hline $\begin{array}{l}\text { Air conditioning systems, } \\
\text { showers }\end{array}$ & Legionella \\
\hline
\end{tabular}

TABLE 2 Clinical features that may be associated with particular tropical infections

\begin{tabular}{|l|l|}
\hline Physical signs & Possible infection \\
\hline Jaundice & $\begin{array}{l}\text { Viral hepatitis, malaria, } \\
\text { leptospirosis }\end{array}$ \\
\hline Maculopapular rash & $\begin{array}{l}\text { Dengue, HIV, syphilis, typhus, } \\
\text { chikungunya }\end{array}$ \\
\hline Eschar & Typhus \\
\hline Urticarial rash & $\begin{array}{l}\text { Acute schistosomiasis } \\
\text { (Katayama fever), } \\
\text { strongyloides }\end{array}$ \\
\hline Bloody diarrhoea & $\begin{array}{l}\text { Shigella, Salmonella, } \\
\text { amoebiasis }\end{array}$ \\
\hline Hepatomegaly & $\begin{array}{l}\text { Enteric fever, leptospirosis, } \\
\text { viral hepatitis }\end{array}$ \\
\hline Splenomegaly & Malaria, visceral leishmaniasis \\
\hline & \\
\hline
\end{tabular}

meningism. Table 2 lists clinical features that may be associated with particular tropical infections.

\section{INVESTIGATIONS}

Initial investigations recommended for febrile travellers are listed in Table 3. Additional targeted investigations should follow once a diagnosis is suspected. Some of these tests are diagnostic, while the results of others, in combination with clinical features, may point to a diagnosis. A large Dutch study of febrile returned travellers noted that malaria was predicted by splenomegaly, thrombocytopenia (platelet count $<150 \times 10^{\circ} / \mathrm{mL}$ ); dengue by rash, thrombocytopenia, and leukopenia (leukocyte count $<4 \times 10^{\%} / \mathrm{mL}$ ); acute schistosomiasis by an eosinophil count $\geq 0.5 \times 10^{9} / \mathrm{mL}$; and enteric fever by splenomegaly and elevated liver transaminases.

All patients with fever who have travelled to a malarious region within the past year must be investigated for malaria. Malaria parasites may be in the blood at very low concentrations, especially in patients who have taken prophylaxis, and the parasites may not be visible in the peripheral blood at different stages of their life cycles. It is

TABLE 3 Initial investigations recommended for returning travellers

\begin{tabular}{|l|}
\hline Full blood count, liver function tests, urea and electrolytes \\
\hline $\begin{array}{l}\text { At least three malaria blood films or rapid diagnostic tests } \\
\text { (RDTs) over two days }\end{array}$ \\
\hline Blood cultures \\
\hline HIV test \\
\hline Urine and stool culture and microscopy \\
\hline $\begin{array}{l}\text { Serology }+/ \text { - polymerase chain reaction (PCR) for dengue } \\
\text { and other arborovirus infections, rickettsiae, Q fever, } \\
\text { Brucella }\end{array}$ \\
\hline Chest X-ray and ultrasound of liver and spleen \\
\hline
\end{tabular}


therefore advisable to take three malaria blood tests over 2-3 days in order to rule out malaria with confidence. Malaria can be diagnosed by microscopy of a blood film, or using a rapid diagnostic antigen test.

Blood cultures should be taken on all patients prior to antibiotics, preferably several sets. These are important for the diagnosis of enteric fever, but also for other bacteraemic illnesses. In the very early days of an HIV infection, the HIV combined antibody and antigen test that is used in UK hospitals may be negative. If clinical suspicion is high, this should be repeated after a few days. Antibody tests are available at UK reference laboratories for many imported infections including rickettsial infections, $\mathrm{Q}$ fever, leptospirosis, Brucella and arbovirus infections (dengue, chikungunya). If there is a high suspicion of VHF infection, blood sampling should be limited to avoid risks to healthcare workers (consult local guidelines).

A raised eosinophil count $\left(>0.45 \times 10^{9} / \mathrm{L}\right)$ is reported in up to $10 \%$ of returning travellers and may indicate a tropical parasite infection. The most commonly identified parasites are intestinal helminths, schistosomes, strongyloides, and filarial infections. These can be diagnosed serologically, or by identification of their eggs in stool, urine or sputum samples. Investigations performed in early infection may be negative and should be repeated after several months. If the eosinophilia persists and no parasitic cause is found, non-infective causes including haematological malignancy and vasculitis should be sought.

\section{MANAGEMENT}

Treatment of many of these infections will require specialist input from infectious diseases physicians and microbiologists. Drug-resistant malaria is widespread and up-to-date treatment guidelines or advice should be followed. For malaria, the British Infection Society treatment guidelines are available. Patients with confirmed non-falciparum malaria may be treated as outpatients, but all those with falciparum or cases where the malaria species is uncertain should be admitted for treatment. Severe malaria may develop within hours, even in migrants to the UK from malaria endemic countries.

Where there is a strong suspicion of enteric fever, antibiotic treatment should be started without delay. A poor clinical response to ciprofloxacin in Asia is now so common that oral azithromycin is the treatment of choice for patients who can take oral medication. If intravenous antibiotics are required then intravenous ceftriaxone should be used until antibiotic sensitivities are known. However the clinical response to ceftriaxone is slow and the symptoms may not resolve for 7-14 days. Most cases of enteric fever from Africa are ciprofloxacin sensitive. Rickettsial infections usually respond promptly to doxycycline, while for dengue the treatment is judicious fluid replacement and supportive care. For many patients with tropical fevers, no diagnosis is made and for others, the diagnosis may not be confirmed for several weeks after presentation, particularly those reliant on serological tests. Empirical treatment will often be indicated, after all appropriate specimens have been collected, and with specialist advice.

Travel-related infections must be notified to Public Health services so that epidemiological data can be collected and where necessary infection prevention and control measures initiated. Finally, we have a duty to our patients to educate them so that they take all available measures to prevent ill health on future travel. This should include advice on vaccine preventable infections, safe sex, food and drink hygiene, malaria prophylaxis and the importance of compliance and insect bite avoidance.

\section{KEY POINTS}

- Malaria, enteric fever and dengue are important and common causes of fever in returning travellers but many travellers will have infections that are not travel related.

- A detailed history and examination is critical to obtaining a diagnosis.

- Malaria may present up to a year after travel and at least three malaria tests over consecutive days are required to exclude the diagnosis.

- Patients with falciparum malaria should be admitted to hospital for treatment.

- Eosinophilia is relatively common in returned travellers and is usually due to parasitic infections.

Web resources for travel advice, disease and outbreak information in different countries

- National Travel Health Network and Centre: www.nathnac.org

- Travax:A-Z of healthy travel: www.travax.nhs.uk

- HPA Migrant Health Guide: http://www.hpa.org.uk/MigrantHealthGuide 


\section{Further reading}

I Bottieau E, Clerinx J, Van den Enden E et al. Fever after a stay in the tropics. Diagnostic predictors of the leading tropical conditions. Medicine 2007; 86:18-25. http://dx.doi.org//0.1097/ MD.0b013e3180305c48

2 Checkley AM, Chiodini PL, Dockrell DH et al. Eosinophilia in returning travellers and migrants from the tropics: UK recommendations for investigation and initial management.J Infect 2010; 60:I-20. http://dx.doi.org/10.1016/j.jinf.2009.11.003

3 Freedman DO, Weld LH, Kozarsky PE et al. GeoSentinel Surveillance Network. Spectrum of disease and relation to place of exposure among ill returned travelers. $N$ Engl J Med 2006; 354:1 19-30. http://dx.doi.org//0.1056/NEJMoa05/33|
4 Johnston V, Stockley JM, Dockrell D et al. Fever in returned travellers presenting in the United Kingdom: recommendations for investigation and initial management. J Infect 2009; 59:1-18. http://dx.doi.org//0.1016/j.jinf.2009.05.005

5 Whetham J, Day JN, Armstrong $M$ et al. Investigation of tropical eosinophilia; assessing a strategy based on geographical area. J Infect 2003; 46:180-5. http://dx.doi.org// 0.1053/jinf.2002.II08

\section{SELF-ASSESSMENT QUESTIONS}

I. A 50-year-old British man who has recently returned from a safari in Kenya presents with fever, lymphadenopathy and a rash. Which ONE of the following statements is TRUE?

A Malaria tests are not required as lymphadenopathy and rash are not recognised features of infection.

B. HIV testing should be performed if he declares a sexual exposure.

C. HIV testing can be done without his consent.

D. Epstein-Barr virus (EBV) infection is not described in patients of this age.

E. You should examine him thoroughly for an eschar.

2. A Scottish teacher becomes unwell returning from a two-month work exchange trip to Malawi. She has a fever, is coughing and has an eosinophil count of $1.0 \times 10^{\circ} / \mathrm{L}$. Stool and urine samples are negative for eggs. Which ONE of the following statements do you most agree with?

A. Malaria tests are not required as eosinophilia is not a recognised feature of infection.

B. The diagnosis is an asthma exacerbation.

C. The diagnosis of a parasitic infection is excluded.

D. Stool and urine will be negative for eggs in early acute schistosomiasis. Serology should be sent and stool and urine samples sent again after one month.

E. The diagnosis is most likely to be histoplasmosis.

3. A 30-year-old Indian man collapses two weeks after arriving in the UK from India. His blood pressure (BP) is $80 / 64 \mathrm{mmHg}$, pulse $64 \mathrm{bpm}$, and he is febrile with abdominal tenderness. Which ONE of the following statements do you most agree with?

A. Intravenous ceftriaxone or azithromycin should be administered after blood cultures have been collected.

B. Intravenous ciprofloxacin should be administered after blood cultures have been collected.

C. He should be resuscitated, and then appropriate therapy started after surgical and medical review.

D. Typhoid vaccination is $100 \%$ effective to prevent infection.

E. The Widal test is the investigation of choice for enteric fever.
4. A nurse presents with a fever and petechial rash, two weeks after returning from working in a rural hospital in Nigeria. She took appropriate malaria prophylaxis throughout her time there. Which ONE of the following statements do you most agree with?

A. Malaria tests are not required as she took malaria prophylaxis.

B. A viral haemorrhagic fever (VHF) risk assessment is not required as she is outside the incubation period for these infections.

C. She is at potential risk of a viral haemorrhagic fever (VHF) infection and should be discussed with the infectious diseases team.

D. HIV seroconversion is the most likely diagnosis.

E. Meningococcal infection is unlikely as Nigeria is not in the African meningitis belt.

5. A 35-year-old Tanzanian man, now living in the UK, develops a fever four weeks after a trip home to visit family. His malaria blood film shows $P$. falciparum at $1 \%$ parasitaemia. His BP, pulse, respiratory rate, and saturations are all normal. Which ONE of the following statements do you most agree with?

A. Chloroquine is the best treatment for his infection.

B. He should be admitted to hospital to start on treatment.

C. Because he grew up in Tanzania, he will be protected from severe complications of malaria and so does not require admission.

D. HIV infection and malaria do not interact together.

E. A viral haemorrhagic fever (VHF) assessment is required.

This paper was originally published as part of the Tropical Medicine module in the RCPE Online Continuing Medical Education Programme. Online CME, including the anwers to these questions, is available to Fellows and Members at: http://www.rcpe.ac.uk 